\title{
The Marrakesh Treaty - Time to End the Book Famine for Visually Impaired Persons Worldwide
}

\author{
Kaya Köklü
}

Published online: 14 October 2014

(C) Max Planck Institute for Innovation and Competition, Munich 2014

Are you able to read these lines? Congratulations! Many people are not, however. They are blind or have a visual impairment that makes the normal reading of texts impossible for them.

There are around 300 million blind and visually impaired persons worldwide. Blind organizations estimate that only about $7 \%$ of all published books are made available in formats accessible for visually impaired persons in developed countries. In developing countries, the situation is even worse as the estimated number of books in an accessible format is only about $1 \%$.

These figures make it obvious that there is a book famine for blind and visually impaired persons, which makes it sometimes very difficult for them to participate in social and cultural life. Even more, they often have to overcome hardly surmountable obstacles to access knowledge, which is particularly essential in terms of education. Thus, it is no wonder that in many countries visual disabilities often are accompanied with low income - a terrible vicious circle. There is no doubt that it is our society's task to tackle and defuse this problem by facilitating the number of copies of works in formats accessible to blind people worldwide.

Providing accessible formats for blind persons normally requires a certain format shifting of the original work. Format shifting of works, however, is subject to copyright laws as it may interfere with the exclusive reproduction right of the copyright holder. Also, online access to and cross-border circulation of these accessible format copies may further interfere with the exclusive rights of distribution and making available of the right holder.

It is therefore understandable that organizations for the blind have called for an international legal regime that, at least from copyright law perspective, facilitates access to knowledge and culture for blind and visually impaired persons.

K. Köklü $(\bowtie)$

Dr. jur.; Senior Research Fellow

Max Planck Institute for Innovation and Competition, Munich, Germany

e-mail: kaya.koeklue@ip.mpg.de 
The World Intellectual Property Organization (WIPO) in Geneva was certainly the right place and body to tackle this issue. But despite the legitimate demand of blind and visually impaired persons, the negotiations on an international treaty were conducted slowly. The negotiations were characterized by the concern of rights holders that a precedent would be set with concessions for the blind and visually impaired that could result in similar demands by other groups. Thus, it was no surprise that particularly at the beginning of the Diplomatic Conference in Marrakesh last year, the fear of those side effects was clearly perceptible.

However, in many informal conversations and discussions between the parties outside the main conference hall, the delegates found themselves in an increasingly constructive atmosphere with a clear and common objective - a mandatory limitation to copyright law for the blind and visually impaired in order to effectively overcome the existing book famine. Who knows, perhaps the increasing willingness to compromise was also due to the fact that with rising media interest, the fear of too far reaching concessions on the part of right holders transformed into a concern of being perceived as the guilty side should the Diplomatic Conference fail.

Whatever the case may be, in the end the delegates agreed on a treaty text that was celebrated by all parties as a breakthrough. Even Stevie Wonder could not resist flying to Marrakesh in order to thank the conference delegates with a private concert.

Meanwhile, more than a year has passed since the Diplomatic Conference in Marrakesh, and the euphoria seems to have somehow evaporated. With the exception of India and El Salvador, currently no other state has ratified the Marrakesh Treaty. Things are developing unexpectedly slowly.

It is, for example, striking that the European Union (EU), one year after the Diplomatic Conference, is still struggling with preliminary matters such as the internal division of competences on how to ratify the Marrakesh Treaty. At least the EU has now signed the Treaty under the presidency of Greece, which, however, is not such a major step in international law and does for the time being not allow conclusions on a rapid up-coming ratification.

The EU would be well advised not to wait too long with ratification and implementation of the Treaty. India and El Salvador have already taken this step. Some other states will probably follow shortly. It is in my view an important opportunity for the EU to send a signal to the world demonstrating its willingness and its ability to proactively fight the book famine for blind and visually impaired persons.

One should bear in mind that the Treaty provides sufficient flexibilities for a tailor-made directive of the EU Commission, which can sufficiently consider the involved interests of stakeholders. To achieve a balance of interests, the EU could limit the exception to works that are not available in an accessible format to reasonable terms on the relevant market. Making use of this flexibility will address the concerns of rights holders who understandably do not wish legal intervention into functioning markets that already serve beneficiary persons.

It is useful to recall that it is in our hands to help end the book famine for blind and visually impaired persons. This concern has gone on for too many years and deserves no further delay. 
Hence, this is my appeal to all decision-makers worldwide: work hard on ratification and implementation of the Marrakesh Treaty and make its provisions apply in practice as quickly as possible. 